\title{
$H$
}

\section{Cognitive Interweave}

E. C. Hurley, DMin, PhD

Introduction: EMDR therapists develop a repertoire of cognitive interweaves $(\mathrm{CI})$ when treating military and veteran clients. This list contains examples of some of the most widely used interweaves. It can be used by therapists looking to expand their list. Interweaves are effective when addressing blocking beliefs and moral injury issues.

Information: Cognitive interweaves are used when: (a) processing is stopped; (b) you are running out of time; and (c) when the client is experiencing intense emotional processing.

Interweaves can make the difference between success and failure when treating blocking beliefs and moral injury issues. Remember, during EMDR basic training, it was stressed that cognitive interweaves are not a reason for transitioning into talk therapy. The therapist offers the interweave - a brief statement or question-but the client may or may not have a verbal response before the therapist says, "Go with that!" Effective cognitive interweaves can enhance the shifting of perspectives during reprocessing.

Client: Cognitive interweaves are used to create a shift in perspective using bilateral stimulation (BLS). The interweave is offered and immediately followed with BLS. Cognitive interweaves are effective in allowing the client to spontaneously respond without thinking through the answer.

\section{COGNITIVE INTERWEAVE EXAMPLES}

What if you had not done it?

Did you plan on it to happen?

How much of it do you have to hold on to it? 
Did your action save lives?

Did you do what you were trained/told to do?

What would you want them (deceased/perpetrator, etc.) to know?

What would you like to say?

Is that $\mathrm{OK}$ (here or in this office)?

What would the adult in you want that little (boy/girl) to know?

What if it was your (your neighbor's) child?

What would your buddy (friend) say to you?

Did you (die)?

Has it helped others?

Who determines ... (whether people live or die)?

Are you so powerful you can override (God's decisions)?

$\mathrm{He} /$ she outweighed you by how much?

It has been how long since that happened?

Can you learn from it?

Did you learn from it?

I'm confused, what if ...?

Is the world a safer place because of ...?

Are you prepared now?

Have you ever ...?

Have there been times you were (did it) alright? 